\title{
COSMOVISIÓN INDÍGENA, PLURALISMO, RAZONAMIENTO JUDICIALY HABEAS CORPUS SOBRE RESTOS MORTALES VELARDE ALCOBA, OSORIO OPORTO Y ÁVALOS ZAMUDIO (Hospital Clínico "Viedma") ${ }^{1}$
}

\author{
ANNETTE MEHLHORN² y RODRIGO CESPEDES ${ }^{3}$
}

\begin{abstract}
Resumen
El fallo comentado concede un habeas corpus por la retención de un cadáver debido al no-pago de una deuda hospitalaria. El Tribunal utiliza la cosmovisión religiosa indígena para estimar que el cadáver tiene dignidad humana y, de alguna manera, "sigue vivo". Lo más interesante de la decisión es que las categorías indígenas no son utilizadas para defender "minorías" sino en un nivel más abstracto (el concepto de "muerte"), no obstante ninguna de las partes se auto-identificaba como indígena o invocó algún elemento de la cosmovisión indígena en sus peticiones.
\end{abstract}

Palabras clave:

\begin{abstract}
The commented ruling granted a habeas corpus for the use of a cadaver as a warranty for the payment of a hospital bill. The Court employs indigenous cosmovision in order to consider that human remains have human dignity and, in same way, the corpse "it is still alive". The most relevant aspect of this decision is that indigenous categories are not utilised in order to protect "minorities" but in a more abstract level (the definition of "death"), despite the fact that none of the parties self-identified as indigenous or included any indigenous cultural element in their claims.
\end{abstract}

Keywords:

DOI: 10.7764/RLDR.6.73

\section{Hechos}

La madre del recurrente fue atropellada y trasladada al Hospital Clínico "Viedma", donde posteriormente falleció. En su calidad de hijo y único familiar cercano, el reclamante solicitó el certificado de defunción y retirar el cuerpo de su madre para que se le diera "cristiana sepultura". La recurrida, trabajadora social del hospital, negó la solicitud arguyendo que existía una deuda no cancelada por concepto de gastos médicos, aunque dicho costo debió haber sido cubierto en forma total por el conductor causante del accidente (quien prometió el pago mediante un título de crédito).

${ }^{1}$ Tribunal Constitucional Plurinacional de Bolivia, Sentencia 2007/2013, Acción de libertad, Expediente 04162-2013-09-AL. Tata Gualberto Cusi Mamani, Magistrado Relator.

2 Candidata a Doctora. Max Planck Institute (Halle).

3 Investigador. Max Planck Institute (Halle). 
Velarde Alcoba, Osorio Oporto y Ávalos Zamudio. Cosmovisión indígena, pluralismo, razonamiento judicial y habeas corpus sobre restos mortales

El accionante recurre de habeas corpus (acción de libertad) al Juez de Garantía y alega la lesión de los derechos a la dignidad, a la libertad y a los "derechos religiosos". Posteriormente sostiene que, si bien la acción de libertad es para derechos de personas vivas; también protege el "derecho a una muerte digna" y los derechos tradicionales y religiosos, todos garantizados por la Constitución. Señala que su familia es Católica y en estos casos acostumbra a realizar misa de cuerpo presente, velatorio y entierro. Asimismo, indica que el responsable es el conductor contra quien se pueden iniciar las acciones legales que correspondan. De esta manera, es innecesario retener el cuerpo o negarse a expedir el certificado médico de defunción, el que "se encuentra sin fecha" (hecho constatado por el Tribunal).

Los recurridos manifestaron que la paciente ingresó al servicio de neurocirugía con un TEC leve, el que se fue complicando por su avanzada edad, permaneciendo 42 días en "estado de emergencia", aplicándosele todos los exámenes y atenciones que el caso ameritaba. Después, la paciente falleció y su cuerpo se trasladó a la morgue. Inmediatamente, el médico procedió a otorgar el certificado de defunción, "que está listo". Enfatizan que en ningún caso se hizo retención del cadáver y que, para el hospital, es oneroso tener el cuerpo por los costos de refrigeración.

El Juez Primero de Sentencia Penal del Departamento de Cochabamba, como Juez de Garantías, desestimó la tutela por razones formales ya que la acción se interpuso después del fallecimiento. ${ }^{4}$ Es imposible representar a un fallecido porque de la muerte se deriva en el fin de la personalidad y la capacidad jurídica para ser sujeto de derechos. Por esta razón que no se puede decidir sobre el fondo.

\section{Sentencia del Tribunal Constitucional Plurinacional}

El Tribunal Constitucional de Bolivia revoca la decisión pronunciada por el Juez Primero de Sentencia Penal del Departamento de Cochabamba y concede la tutela solicitada. En consecuencia, ordena entrega inmediata del cuerpo de la madre del recurrente. A su vez, exhorta al Hospital Clínico Viedma a que, en el futuro, no incurra en actos similares a los denunciados en el proceso en comento y sujetarse al marco de los derechos constitucionales según los siguientes fundamentos:

(a) Bolivia se constituye en un Estado Unitario Social de Derecho Plurinacional Comunitario. La nueva Constitución marca una ruptura respecto al constitucionalismo clásico, mono-cultural y occidental concebido por las élites políticas. En este proceso expresa la voluntad de los pueblos indígenas, creando una nueva institucionalidad, transversalizada por lo plurinacional. La Carta Fundamental Boliviana tiene características que la distinguen y dan cuenta de un constitucionalismo que no tiene precedentes en la historia. Asimismo, sus intérpretes deben ser fieles a sus principios y así dar vida a las normas constitucionales, entre ellas, el pluralismo jurídico y la descolonización.

\footnotetext{
${ }^{4}$ Resolución Nr. 08 de 16 de Julio de 2013.
} 
ISSN 0719-7160

(b) La construcción de la institucionalidad plurinacional comienza con el desmontaje de las lógicas de colonialidad, desmitificando la idea de que impartir justicia es solamente una potestad extremadamente formal y cuasi sacramental. Por el contrario, administrar justicia se asume como un servicio al pueblo, concebida como facultad/obligación. Por esta razón, más la supremacía constitucional, la protección de los derechos fundamentales debe ser realizada por encima de las formalidades e inclusive de las leyes, pues, la eficacia de un derecho no depende de la medida y los términos trazados por una ley ni las formalidades exigidas para su tutela, sino más bien, en la medida y en los términos trazados por la misma Carta Fundamental. La interpretación conforme a los Pactos Internacionales sobre Derechos Humanos y los principios pro homine y de progresividad supone la superación de la idea formalista del sistema jurídico para asegurar la eficacia máxima de los derechos fundamentales. En efecto, los formalismos extremos pueden obstaculizar la plena vigencia de las libertades constitucionales. En ese sentido, si bien dentro del ámbito de protección de la acción de libertad se encuentran previstos sólo determinados derechos; empero, es posible efectuar el análisis de otras libertades cuando las mismas tengan conexión con los que se encuentran bajo la tutela de la acción de libertad. El informalismo, la celeridad y el impulso de oficio son características de esta acción y tienden a garantizar el acceso a la justicia.

(c) Corresponde al Tribunal Constitucional Plurinacional romper esas prácticas coloniales, aportar al proceso de interpretación intercultural de las libertades fundamentales y cautelarlos poniendo énfasis en los derechos colectivos y de los pueblos indígenas.

(d) La Constitución y la Convención Inter-Americana de Derechos Humanos protegen la dignidad humana. Ésta se vulnera por los actos o disposiciones que degraden a la persona a un nivel de estima incompatible con su naturaleza, cualquiera sea el lugar o situación en la que se encuentre. Por lo tanto, la persona no puede ser tratada como un medio, sino como un fin en sí misma y, consecuentemente, están proscritos aquellos actos o medidas que convierten a la persona en un instrumento para la consecución de fines ajenos a su valor intrínseco. En este caso hay una lesión al derecho a la dignidad de una persona que se encontraba con vida.

(e) Desde una concepción eminentemente civilista, podría sostenerse, conforme lo hace el Código Civil, que la muerte pone fin a la personalidad; por tanto, ya no se sería titular del derecho a la dignidad, y que tampoco podría representarse a un fallecido en la defensa de derechos fundamentales, por ser éstos inherentes a una persona física viva. Sin embargo, dicha concepción debe ser matizada a la luz de la importancia que reviste la muerte y los diferentes significados que tiene dentro de una comunidad; aspectos que van más allá del enfoque civilista y que permiten afirmar que la dignidad de la persona transciende a la muerte. El cuerpo humano no se disocia tan fácilmente de lo que en vida representó, tanto para la familia como para la comunidad, quienes preservan la dignidad de sus seres queridos aún después de la muerte, dignidad que se encarna en los restos mortales. Diferentes culturas y religiones guardan respeto a los restos mortales y establecen diversos ritos que forman parte del derecho a la libertad de espiritualidad, religión y culto. Al impedir recoger el cadáver, se está impidiendo que la familia exprese íntimamente su dolor por la pérdida de un ser querido, y en su caso, realice los actos que la costumbre y su religión mandan para el velatorio y el entierro del difunto, hecho que evidentemente no puede ser tolerado por este Tribunal. Ya Antígona, la obra de Sófocles, cuestionó la validez de las leyes 
Velarde Alcoba, Osorio Oporto y Ávalos Zamudio. Cosmovisión indígena, pluralismo, razonamiento judicial y habeas corpus sobre restos mortales

positivas, cuando reclamó ante el Rey que le devolvieran el cuerpo de su hermano muerto en batalla para darle sepultura, alegando para ello una ley universal, superior a la del mismo Rey, que le permitiría acceder a ese derecho. ${ }^{5}$

(f) Desde la perspectiva de los pueblos indígenas, el fallecimiento no implica la muerte de la persona, pues ésta permanece en la comunidad, sigue existiendo de un modo intangible. La vida es energía que fluye perpetuamente. La muerte es simplemente el paso de un espacio del cosmos a otro, a otro ciclo vital. La familia y la comunidad se reúnen para acompañar al moribundo y despedirlo en esa fase y su tránsito a la siguiente. La realización de ritos y las ceremonias que coadyuvan a lograr dicho fin. Esa vida también se considerada sagrada, porque no se reduce al simple funcionamiento de los órganos vitales. Esta traslación de energía es concebida en Occidente, como "la muerte" (un punto final); para los pueblos indígenas, se le ha denominado "la otra vida". En la concepción indígena se concibe que todos continuamos conectados con nuestros antepasados, que son considerados como deidades sagradas y continúan unidos con la comunidad humana y la naturaleza. Desde esta concepción, entonces, no existe la muerte como tal, sino la transición en diferentes momentos y espacios cósmicos, concibiéndose así la vida de manera holística en que todos los seres vivos son parte del cosmos, y como tales llegan a constituirse en la comunidad cósmica, en cualquiera de los espacios reconocidos por la tradición indígena: aka pacha, mankha pacha, alax pacha y hanan pacha. De allí la celebración del Día de los Muertos en Latinoamérica. Por lo tanto, desde el pensamiento indígena, no existe la conversión del cuerpo de "sujeto en objeto"; pues, en su cosmovisión ancestral, seguimos siendo sujetos más allá de la "muerte" como es concebida en Occidente. Otras religiones, como la Católica, predican la dignidad de las personas como hijos de Dios. La muerte no termina la relación con Dios, pues el centro de la fe cristiana es la creencia en una vida eterna. Por tal motivo, la religión Católica cree en la santidad del cuerpo.

(g) La jurisprudencia constitucional, ha sido uniforme en otorgar tutela a través de la acción de libertad, frente a retenciones indebidas en centros hospitalarios públicos, bajo el argumento que, en dichos supuestos se lesiona el derecho a la libertad personal, pero también se lesiona el derecho a la dignidad. En el caso de las deudas hospitalarias, el Tribunal ha reiterado la prohibición de la "prisión por deudas".

\footnotetext{
${ }^{5}$ La obra de Sófocles dramatiza el viejo tema de la contradicción entre la ley positiva y el derecho natural, principios morales tan básicos que deben ser reconocidos por la ley vigente para considerarse como tal y ser vinculante. La tragedia, que es bastante más compleja que la simplificación anterior, explora varios asuntos. Primero, si a Polinices (quien condujo ejércitos en contra de su propia ciudad aliándose con una potencia extranjera; o sea, traición; previamente había violado a su mujer) se les deben dar rituales funerarios (negárselos sería como una pena infamante para un crimen de lesa humanidad; Antígona piensa que los rituales funerarios "no se le deben negar a nadie", porque atentaría contra la dignidad más básica, incluso la de un traidor). Segundo, si Antígona, que lo enterró desafiando la ley positiva, debería ser castigada (ella es una especie de objetora de conciencia que practica la desobediencia civil; aunque su parentesco con el traidor no la hace imparcial). Tercero, si las medidas de Creonte (negar el funeral y sancionar a la objetora de conciencia), son razonables o arbitrarias (indudablemente quiere desestimular la traición a la Polis y tolerar una infracción a su mandato frustraría ese propósito, lo que parece razonable; aunque también quiere defender su propio poder. Creonte no es un simple tirano). El impacto en la cultura ha sido tan profundo que ha sido comentada por Heidegger, re-hecha por Brecht y musicalizada por Mendelssohn, Orff y Honegger. La figura de Antígona podemos fácilmente asociarla con Henry David Thoreau, Rosa Parks, Martin Luther King Jr., Mohamed Ali y Ghandi.
} 
ISSN 0719-7160

(h) En la cotidianeidad de la cruda realidad boliviana, el menoscabo de la dignidad, el abuso institucional y la arbitrariedad contra el individuo no es ajeno a muchos enfermos y familiares. Éstos deben lidiar con la insensibilidad y el pragmatismo crudo del interés pecuniario, sumándose al desconsuelo e impotencia de los familiares el maltrato y abuso de funcionarios públicos y particulares. El habeas corpus como medio procesal debe enmarcarse en ese contexto y ha servido en el pasado para, garantizar la libertad en casos de pacientes dados de alta que se retienen para coaccionar el pago de servicios prestados. Así, libertad personal, libertad de culto y dignidad están unidas, porque son derechos interdependientes y conexos. En este caso, la persona, su cuerpo, se constituye en un instrumento de presión para el cumplimiento de obligaciones pecuniarias, lo que ciertamente lesionaba la dignidad humana, al considerarla como un simple medio para lograr la cancelación de la deuda. Por lo tanto, es preciso extender el ámbito de protección de la acción de libertad a los supuestos en los cuales se utilice el cuerpo de una persona fallecida como un medio para lograr la satisfacción de fines económicos; entendiendo que en esos casos, es posible que los familiares presenten la acción de libertad solicitando la protección del derecho a la dignidad del occiso, tanto de quien ya no se encuentran en la comunidad humana, como de los propios familiares, así como el derecho a la libertad de espiritualidad, religión y culto de los familiares, a partir del valor que culturalmente tiene el cuerpo de la persona fallecida para los deudos.

\section{Comentario}

La situación descrita parece sacada de un libro de realismo mágico latinoamericano por lo surrealista. Un cuerpo humano utilizado como garantía para el pago de obligaciones pecuniarias derivadas de un servicio de salud y un certificado de defunción sin fecha para presionar al único familiar, que ni siquiera era responsable de la deuda. La decisión comentada tiene varios aspectos relevantes: el tratamiento de la dignidad humana, la informalidad procesal, la extensión del habeas corpus y la inclusión de la cosmovisión indígena en la fundamentación del fallo, etc.

La dignidad humana se ha entendido como el supremo valor del derecho, como aparece señalado en múltiples constituciones y tratados. ${ }^{6}$ Frecuentemente se nombra en cuestiones relacionadas con derechos reproductivos, ${ }^{7}$ la prisión perpetua $\sin$ posibilidad de beneficios, ${ }^{8}$ las condiciones

${ }^{6}$ Artículos 1 y 2 de la Declaración de Derechos Humanos de la ONU, Artículo 1 de la Carta de Derechos Fundamentales de la Unión Europea; Artículo 1(1) de la Constitución Alemana; Artículo 10 de la Constitución Española; Artículo 1(1) de la Constitución Chilena; preámbulo, Artículos 8(II), 9(2) y 15 de la Constitución de Bolivia.

7 Por ejemplo, la Assisted Human Reproduction Act (2004) de Canadá; o la decisión de la Corte Constitucional Federal Alemana BVerfGE 39,1 (1975) que declaró inconstitucional la ley de aborto de 1975 porque los embriones tenían dignidad humana.

${ }^{8}$ La decisión de la Corte Constitucional Federal Alemana BVerfGE 45, 187 (1977) que declara que la cadena perpetua sin posibilidad de libertad condicional atenta contra la dignidad humana. 
Velarde Alcoba, Osorio Oporto y Ávalos Zamudio. Cosmovisión indígena, pluralismo, razonamiento judicial y habeas corpus sobre restos mortales

laborales, ${ }^{9}$ los abusos de la libertad de expresión, ${ }^{10}$ etc. El concepto de dignidad está íntimamente ligado a la idea de derechos fundamentales, ya que la mayoría de los instrumentos internacionales relativos a los derechos humanos se refieran a este concepto. ${ }^{11}$ Sin embargo, su rol en el derecho ha sido debatido. Se ha argumentado que el concepto no provee un principio universal que sirva de base para decidir judicialmente asuntos sobre derechos fundamentales, en el sentido que existe poco consenso sobre lo que la dignidad sustantivamente requiere dentro de una jurisdicción específica (por ejemplo, la boliviana) o comparativamente entre varias jurisdicciones. ${ }^{12}$ Esta afirmación también tiene vigencia desde un enfoque intercultural.

La Constitución Boliviana menciona la dignidad en su Artículo 8 como uno de los valores en los que se sustenta el Estado. Además, su Artículo 9(2) declara como fin y función del Estado el "Garantizar el bienestar, el desarrollo, la seguridad y la protección e igual dignidad de las personas, las naciones, los pueblos y las comunidades, y fomentar el respeto mutuo y el diálogo intracultural, intercultural y plurilingüe". La dignidad se menciona también en su Artículo 21(2) al señalar que las bolivianas y los bolivianos tienen, entre otros, derecho "a la privacidad, intimidad, honra, honor, propia imagen y dignidad". Finalmente, su Artículo 22 declara que: "La dignidad y la libertad de la persona son inviolables. Respetarlas y protegerlas es deber primordial del Estado."

El fallo en cuestión es un precedente crucial que ayuda a definir el concepto de dignidad humana en el contexto boliviano. Un aspecto que debe destacarse es que acentúa el elemento colectivo de la dignidad humana, que normalmente se ha concebido en su naturaleza individual. ${ }^{13}$ El fallo se basa fundamentalmente en los efectos que la muerte produce en la familia y en la comunidad. El Tribunal Constitucional Boliviano ha hecho un extenso desarrollo de la dimensión colectiva de los derechos humanos en relación a los pueblos indígenas, sobre el cual se sustenta esta decisión. El Tribunal y la literatura académica, que han acompañado el proceso político/legal boliviano, han sondeado la posibilidad de impulsar un cambio en la conceptualización de nociones legales y

${ }^{9}$ En Chile, la Dirección del Trabajo ha dicho que resulta jurídicamente improcedente controlar el tiempo que los trabajadores destinan al uso de los servicios higiénicos, Dictamen Nr. 4.541/319 del 22/09/1998. También, que el uso del polígrafo aplicado a la selección de personal, así como a los trabajadores que actualmente se desempeñan en la empresa, para los fines de prevenir delitos, es contrario al orden jurídico laboral chileno porque atenta contra la dignidad, Dictamen Nr. 0684/050 del 06/02/1997.

${ }^{10}$ Contra Pinto Zepeda (1993), Corte Suprema, Casación fondo, RDJ T 90 Nr. 1 (1993), sec. IV, pp 66-ss. Se condena por abusos de publicidad al director del "Diario Austral", por difundir el hecho falso de que una mujer padecía de SIDA producto de su promiscuidad, lo que afecta su dignidad, constitucionalmente protegida.

${ }^{11}$ GROS ESPIELL Héctor, "La Dignidad Humana en los Instrumentos Internacionales sobre Derechos Humanos en Anuario de Derechos Humanos", Nueva Época (2003) Vol. 4, p 200; SANTIAGO SALAME, Soraya y GUARAYO LLANOS, Humberto, Interdialogando: Hacia la construcción plural del Derecho desde la cosmovisión de la Nación Yampara, Konrad Adenauer Stiftung, 2014, p 110.

12 MCCRUDDEN, Christopher, "Human Dignity and Judicial Interpretation of Human Rights", European Journal of International Law (2008) Vol. 19 Issue 4, pp 655-724.

13 SANTIAGO SALAME, Soraya y GUARAYO LLANOS, Humberto, Interdialogando: Hacia la construcción plural del Derecho desde la cosmovisión de la Nación Yampara, Konrad Adenauer Stiftung, 2014. 
sociales, separándose de las ideas liberales-individualistas privilegiando una aproximación más colectiva, que no puede ser definida a priori. $^{14}$

El Tribunal ve una clara violación a la dignidad y extiende el ámbito de la acción del habeas corpus. ${ }^{15}$ La línea argumental fundamental es que, en varias tradiciones religiosas y culturales, la dignidad de las personas trasciende a la muerte y se encarna en los restos mortales. Esto vuelve el trato respetuoso del cuerpo crucial en varias culturas y comunidades diferentes. El Tribunal destaca el valor de los rituales mortuorios y el culto a los ancestros es común a muchas culturas. Hay un particular énfasis en la cosmovisión indígena sobre la muerte, según la cual ésta no existe como tal. La sentencia basa su línea argumental en la premisa de que el cadáver no debe ser tratado de manera tan diferente como un ser humano vivo y que, en consecuencia también en este caso se aplica, lo que ha sido establecido por la jurisprudencia constitucional para personas vivas. La jurisprudencia constitucional boliviana ha sido uniforme en otorgar la tutela a través del antes recurso de habeas corpus y ahora acción de libertad, frente a retenciones indebidas en centros hospitalarios públicos, bajo el argumento que, en dichos supuestos se lesiona el derecho a la libertad personal, pero también la dignidad. El Tribunal pone acento en el rol tutelar que tiene la jurisdicción sobre los derechos fundamentales, que son interdependientes y conexos, extendiendo el ámbito de protección de la acción de libertad a los supuestos en los cuales se utilice el cuerpo de una persona fallecida como un medio para lograr la satisfacción de fines económicos u otros intereses sobre la base que representaría una violación de la dignidad del fallecido y sus familiares así como de la libertad de espiritualidad, religión y culto de los familiares y seres queridos.

Todo este argumento se desarrolla también en el espíritu de la desformalización en la protección de los derechos fundamentales. Las formas procesales son instrumentales, es decir, existen sólo para lograr un objetivo, no son un fin en sí mismas. Si un Tribunal rechaza peticiones fundadas simplemente por falta de formas vacías de contenido se impide el acceso a la justicia e incumple su labor cautelar. La rigurosa adherencia a la letra de la ley puede atentar contra su espíritu y así faltar al poder/deber asignado por la Constitución. La aplicación estricta de las reglas de representación judicial aquí interfiere con la tutela de un derecho fundamental lesionado. El derecho, siguiendo esta línea de pensamiento, pierde su sacralidad y rigidez (cosa que resalta el fallo) y se vuelve maleable, "un derecho en devenir". ${ }^{16}$ Zagrebelsky señala que en un contexto pluralista, el derecho no puede verse como un simple "dato"; "en los contextos pluralistas es necesario hacer el procedimiento 'discursivo' y 'persuasivo' a fin de alcanzar el punto de máxima

${ }^{14}$ WOLKMER, Antonio Carlos, Pluralismo jurídico: nuevo marco emancipatorio en América Latina, en Derecho y sociedad en América Latina: Un debate sobre los estudios jurídico críticos (M. Villegas, \& C. Rodríguez, Eds.), ILSA, 2003, pp 247-259.

${ }^{15}$ Históricamente, la frase habeas corpus ad subjiciendum originada en el derecho romano, y de allí a algunos textos medievales, implica literalmente una orden al captor de mover materialmente el cuerpo a la presencia del tribunal para su examen.

${ }^{16}$ ROJAS TUDELA, Farit, "Hacia una nueva gramática constitucional”, Revista Ciencia y Cultura (2015) Nr. 26, pp 147-166. 
Velarde Alcoba, Osorio Oporto y Ávalos Zamudio. Cosmovisión indígena, pluralismo, razonamiento judicial y habeas corpus sobre restos mortales

realización de los principios en juego." ${ }^{17}$ En realidad, el principio de oficialidad en la protección de los derechos fundamentales y la no-formalización llegan a una extensión máxima en esta decisión. El Tribunal entiende que el habeas corpus protege la dignidad como derecho conexo a la libertad y, como parte de la cosmovisión indígena y el valor cultural de los restos mortales, el fallecido "sigue vivo" de alguna manera y puede tutelarse por medio de esta acción. De la misma forma, se extiende el razonamiento de la prohibición de la prisión por deudas a la retención del cadáver.

Como decíamos, un elemento central del fallo es la elaboración de la cosmovisión indígena relativa a la muerte. Esto es particularmente interesante ya que ninguna de las partes en conflicto se autoidentifica como indígena ni argumentan en base a esa categoría. En efecto, el reclamante y la fallecida eran Católicos. El componente de la cosmovisión indígena no es parte de los derechos invocados sino del elegante y original razonamiento del Tribunal. Reinterpretar un concepto tan fundamental como la muerte, en el ámbito jurídico, incluyendo elementos de las cosmovisiones indígenas en el razonamiento del Tribunal pese a que ninguna de las partes se identificaba como indígena constituye un fenómeno complejo e interesante. Este aspecto da un nuevo y original enfoque al debate sobre la jurisdicción plurinacional o intercultural ya que no limita la inclusión de cosmovisiones nativas ancestrales a los casos "tradicionales" sobre derechos indígenas.

La Constitución Boliviana ha despertado interés en las ciencias sociales y la doctrina jurídica, fundamentalmente por el carácter fundacional que ha concedido al pluralismo, los derechos indígenas y sus epistemologías. La Constitución Boliviana tiene un texto ambiguo que para muchos no estaba a la altura de las expectativas de la asamblea constituyente. ${ }^{18}$ Sin embargo, esta Carta Fundamental incluye elementos con gran potencial para re-pensar la nociones de Estado y derecho. Muchos autores han celebrado la consagración de la descolonización y la plurinacionalidad. De acuerdo con Alberto del Real Alcalá "la Constitución Boliviana quiebra el modelo de Estado propio del 'liberalismo homogeneizador decimonónico' y, por consiguiente, quiebra la nación jacobina, abstracta, uninacional, centralista y unicultural (...) que en la práctica ha fulminado e invisibilizado cualquier diferencia étnica, cultural o nacional". ${ }^{19}$ En teoría el Estado Boliviano, por lo tanto, no meramente "reconoce" los derechos indígenas sino que es constituido y definido por indígenas y otros colectivos. ${ }^{20}$ Muchas veces, las cosmovisiones indígenas son

17 ZAGREBELSKY, Gustavo, El Derecho Dúctil, Editorial Trotta, 2007, p 14.

18 "Entrevista a Pablo Mamani", Boletín Bolivia (Augusto/Septiembre 2011), pp 23-29; GARCÉS, Fernando, "The Domestication of Indigenous Autonomies in Bolivia: From the Pact of Unity to the New Constitution", en Remapping Bolivia: Resources, Territory, and Indigeneity in a Plurinational State (Nicole Fabricant and Bret Gustafson, Eds.), NM: School for Advanced Research, 2011, pp 46-67.

19 Del REAL ALCALÁ, Alberto, "La construcción de la Plurinacionalidad desde las resoluciones del nuevo Tribunal Constitucional Plurinacional de Bolivia: Desafíos y resistencias", en Hacia la construcción del Tribunal Constitucional Plurinacional, Memoria Conferencia Internacional, CONCED GTZ, 2010.

20 YRIGOYEN, Raquel, "El horizonte del constitucionalismo pluralista: del multiculturalismo a la descolonización", en El Derecho en America Latina: Un mapa para el pensamiento jurídico del siglo XXI (César Rodríguez Garavito, Editor), Siglo Veintiuno, 2011, p 149. 
incluidas como un elemento adicional dentro de una argumentación "liberal" y sólo cuando personas indígenas están involucradas. Este caso se aparta de esta tendencia. Para justificar la expansión del habeas corpus se utilizan tanto la cosmovisión cristiana como la indígena. La interpretación intercultural de valores y derechos supremos y, en general, el movimiento hacia el pluralismo epistémico y la interculturalidad como parte del proyecto de descolonización ha sido enfatizado por la literatura socio-legal. Según Santiago Salame y Guarayo Llanos, "el Tribunal Constitucional Plurinacional tiene la tarea no sólo de consolidar una materialización de la Constitución como texto escrito, sino esencialmente de los valores plurales supremos insertos en ella; pero además, uno de los roles esenciales de este órgano es generar una lectura plural de los derechos humanos que no se agota ya en la tutela individual o social de los mismos, ni siquiera en la tutela de los derechos colectivos de los pueblos indígenas sino esencialmente en la interpretación plural e intercultural de todos y cada uno de los principios, valores y derechos contenidos en nuestra Constitución." ${ }^{21}$ Es sintomático que, en este fallo, las cosmovisiones indígenas no son utilizadas para defender "minorías" sino en un nivel más abstracto, en la misma forma en que se han utilizados nociones filosóficas o religiosas occidentales en otros casos. No obstante, se debe mencionar que en la propia naturaleza del derecho recae el poder de (re-)definir nociones y que las complejidades que se esconden detrás de un concepto como "cosmovisión indígena" no pueden ser exploradas en plentitud en la narrativa legal. Este fallo es un ejemplo relevante para la discusión de la posibilidad simultánea de presentar narrativas plurales a través del derecho, por un lado, y el peligro de esencialización que es inherente a la ley (y tal vez incluso a las decisiones más reflexivas) y sus tendencias reductivas que no pueden hacer justicia a las complejidades y el carácter disputado de conceptos como "indígena" o "cosmovisión", por el otro. $^{22}$

Para concluir, en un momento en el que la realidad boliviana post-constituyente enfrenta cada vez más críticas, este fallo nos recuerda la necesidad de profundizar el debate sobre las potencialidades del derecho. Esta sentencia, muy original, puede contribuir a las discusiones sobre las aproximaciones legales a la religión y la pluralidad, así como a los debates académicos sobre las re-conceptualizaciones del derecho.

Sin embargo muchas voces críticas ponen énfasis en una gran diferencia entre discurso y letra por un lado y la realidad por otro lado; NUNEZ DEL PRADO, José, Utopía indígena truncada: Proyectos y praxis de poder indígena en Bolivia Plurinacional, CIDES/UMSA, 2015

${ }^{21}$ SANTIAGO SALAME, Soraya y GUARAYO LLANOS, Humberto, Interdialogando: Hacia la construcción plural del Derecho desde la cosmovisión de la Nación Yampara, Konrad Adenauer Stiftung, 2014, pp 35-36.

22 ROBBINS, Bruce; STAMATOPOULOU, Elsa, Reflections on culture and cultural rights, The South Atlantic Quarterly, 2004, Nr. 2, S. 419-434; SIEDER, Rachel; WITCHELL, Jessica, Advancing indigenous claims through the law: reflections on the Guatemalan peace process. Culture and rights: anthropological perspectives, 2001. 